\title{
UN ASPECTO DE LA RECEPCIÓN LITERARIA DE MARCO BRUTO: LA RESISTENCIA CONTRA EL ORDEN CÓSMICO
}

\author{
ONE ASPECT OF THE LITERARY RECEPTION OF BRUTUS: \\ THE RESISTANCE TO THE COSMIC ORDER
}

\author{
Rafael Sáseta Naranjo \\ Universidad de Sevilla
}

\begin{abstract}
Resumen: Debido a la interpretación medieval providencialista de la victoria de Julio César y Octavio Augusto como manifestación de la voluntad divina, Marco Junio Bruto, siendo el último de los oponentes al poder autárquico que impusieron, recibió diferentes interpretaciones a lo largo de la historia de la literatura. En primer lugar sería admirado por las fuentes clásicas, después condenado por la mentalidad cristiana, para llegar finalmente a convertirse en símbolo de la rebelión contra el orden divino y moral durante la crisis del ideal clásico en el Romanticismo.
\end{abstract}

Palabras clave: Bruto, Augusto, Dante, Leopardi, Prometeo.

Abstract: Due to the medieval providentialist reading of the victory of Julius Caesar and Octavian Augustus as a manifestation of divine will, Marcus Junius Brutus, the last opponent of the autocratic power that the latter two imposed, would be the object of many interpretations along the history of literature. Firstly, Brutus would be be admired in classical sources, later condemned by christian mentality, and finally made a symbol of rebellion against the divine and moral order when the crisis of the classical ideal took place in the Romantic period.

Keywords: Brutus, Augustus, Dante, Leopardi, Prometheus.

La biografía que el autor griego Plutarco dedicó al héroe republicano Marco Junio Bruto Cepión (ca. 85-42 a. C.) en sus Vidas Paralelas, nos presentaba la imagen de un personaje intachable, que, a pesar de haber sido el principal ejecutor en la conspiración que asesinó al vencedor de la gran guerra civil romana del 49 al 45 a. C., y haber luchado contra su heredero Octavio, el fundador del poder autocrático de los emperadores, no sería reprobado después de muerte, convirtiéndose en ejemplo de resistencia y determinación personal en la Antigüedad. Este hecho, en cierta medida contradictorio, iba a ajustarse, 
no obstante, a las directrices políticas del régimen de Augusto, que se complacía en mostrar hacia sus oponentes una modélica clemencia ${ }^{1}$, no debilitando con ello la percepción de su poder, sino realzándola. A propósito de Bruto, en el pasaje que ofrecemos a continuación, nuestro biógrafo nos daba un ejemplo paradigmático de este comportamiento, cuando, durante su visita a Milán, en la Galia Cisalpina, el princeps se sorprendía de encontrar todavía en pie una estatua del asesino de su padre adoptivo Julio César, contra el que había combatido:

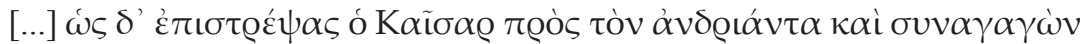

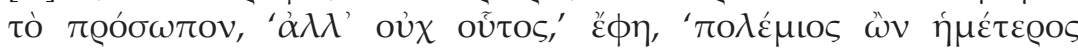

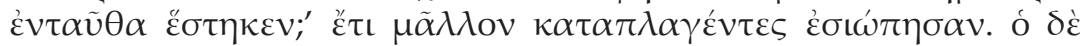

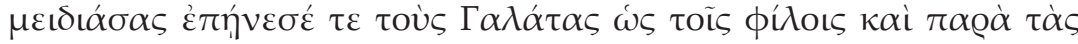

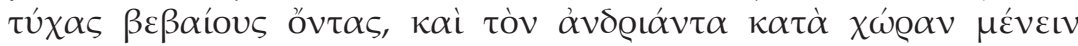

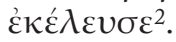

En el ámbito literario, la época de Augusto supondría un viraje hacia un estilo encomiástico, que le proporcionaría la base de su legitimación política. Su régimen sería elevado a la categoría de necesidad histórica, considerándose como el resultado de un designio divino. Por eso el gran Virgilio ponía en boca del espectro de Anquises, al ser visitado por su hijo Eneas en el mundo infernal, la premonición de que por la inexorable decisión del hado, Roma sería la heredera de la gran ciudad de Troya, y Eneas, el último de los héroes troyanos, el fundador y antecesor directo de la familia Julia, destinada a expandir su dominio sobre los demás pueblos del mundo: "Tu regere imperio populos, Romane, memento/ (hae tibi erunt artes), pacique imponere morem, /parcere subiectis et debellare superbos"3.

Con la derrota de los asesinos de César, Octavio quedaría libre para ir completando la progresiva implantación de su poder absoluto, secuestrando de facto las instituciones republicanas y poniéndolas al servicio de sus intereses, por lo que la muerte de su enemigo Bruto podría reinterpretarse como el punto de inflexión entre dos épocas, ya fuera bajo una óptica positiva o negativa. Cuando

1 Antes de que Augusto adoptara este concepto de su predecesor Julio César, como una de las bases de su política, fue elevado a la categoría de religión de Estado, cuando en el año 45 a.C. el Senado decretó construir un templo en honor a la Clementia Caesaris, como abstracción divinizada, tal como apreciamos en la moneda acuñada por Publio Sepulio Macer, en cuyo reverso puede observarse dicho templo, cf. Novillo López (2013: 746).

2 Plut. Comp. Dio. Brut. 5, 2, "César, entonces, volviéndose hacia la estatua, frunció el ceño y dijo: “`No es enemigo nuestro éste que está aquí en pie?”. Todavía atónitos, los magistrados callaban. Él, sonriendo, felicitó a los galos por permanecer fieles a sus amigos, incluso a los que sufrieron el infortunio, y ordenó que la estatua permaneciese en su sitio". Trad.Juan Pablo Sánchez Hernández y Marta González González, Madrid: Gredos, 2009.

3 Verg. Aen. VI, 851-853, “Tú, romano, recuerda tu misión: regir a los pueblos con tu mando. Éstas serán tus artes: imponer leyes a la paz, respetar a los súbditos y aniquilar a los insurrectos”. 
siglos después el poder imperial llegara a su fin, no lo hizo, sin embargo, el recuerdo de sus grandes hombres y hazañas. Como base cultural, integradora de diversos pueblos, la estructura jurídico-administrativa romana sería herencia imperecedera para el conjunto de reinos altomedievales asentados sucesivamente en su antiguo territorio, gérmenes de las futuras naciones modernas. Este hecho explicaría que el gran poeta Dante Alighieri no considerase todavía la existencia de una separación histórica cualitativa respecto de su propia época y la época clásica, para expresar lo cual reutilizó en la Commedia la estructura del poema virgiliano, revistiéndolo de un pensamiento cristiano, actualizándolo de esta manera hasta su propia época.

El dominio que César y sus sucesores habían impuesto sobre el resto de culturas europeas sería reinterpretado por il Sommo Poeta no meramente como un episodio más de la humanidad, sino como un paso histórico fundamental dentro de un plan diseñado por Dios, que debía llevar a los diferentes pueblos a un gobierno único o monarchia universal, como un escenario necesario para la correcta posterior difusión de su palabra. La unificación política bajo el poder de Roma se convierte en la estructura social que hace posible la cristianización europea; y su sello literario, la Eneida virgiliana, tomaría un valor dentro de ese modelo de pensamiento. La característica definitoria de su protagonista, la pietas del héroe Eneas, padre fundador de la dinastía Julio-Claudia, se reinterpretaría como el antecedente de la piedad cristiana, creándose con ello la justificación necesaria para aceptar la dominación de Roma como una necesidad moral:

Dico igitur ad questionem quod romanus populus de iure, non usurpando, Monarche offitium, quod 'Imperium' dicitur, sibi super mortales omnes ascivit. [...] Hiis itaque ad evidentiam subassumpte prenotatis cui non satis persuasum est romani populi patrem, et per consequens ipsum populum, nobilissimum fuisse sub celo? Aut quem in illo duplici concursu sanguinis a qualibet mundi parte in unum virum predestinatio divina latebit? ${ }^{4}$

Precisamente porque el Imperio se desarrolló conforme al derecho y a la decisión de Dios, continuaba el poeta, fue posible el sacrificio de Cristo, y mediante él, la expiación del pecado de Adán, condición necesaria para el desarrollo del Cristianismo. Con ello, éste adopta el sentido de una conclusión lógica y necesaria de los parámetros que venían dados por el judaísmo. Para que se diera esa expiación, era necesaria la intervención de un “juez competente”, con

4 Dante Alighieri $(1965,176)$. "Con referencia a esta cuestión digo también que el pueblo romano se arrogó conforme a derecho, y no por usurpación, el oficio de la Monarquía, llamado "Imperio", sobre todos los mortales. (...) Por tanto, con todos estos datos para aclarar la premisa, ¿quién puede dudar de que Eneas fue el padre del pueblo romano, y de que, consecuentemente, el mismo pueblo fue el más noble que haya existido bajo el cielo? O, dicho de otra manera, ¿a quién se le ocultará la predestinación divina de este hombre único, a la vista de la doble concurrencia en él de la nobleza de la sangre, desde todas las partes del mundo?”. Trad. Laureano Robles Carcedo y Luis Frayle Delgado, Madrid: Tecnos, 1992. 
la potestad de juzgarlo, recayendo esta responsabilidad sobre la administración romana:

Si ergo sub ordinario iudice Cristus passus non fuisset, illa pena punitio non fuisset. Et iudex ordinarius esse non poterat nisi supra totum humanum genus iurisdictionem habens, cum totum humanum genus in carne illa Cristi portantis dolores nostros, ut ait Propheta, puniretur. Et supra totum humanum genus Tyberius Cesar, cuius vicarius erat Pilatus, iurisdictionem non habuisset, nisi romanum Imperium de iure fuisset. Hinc est quod Herodes, quamvis ignorans quid faceret, sicut et Cayphas cum verum dixit de celesti decreto, Cristum Pilato remisit ad iudicandum ut Lucas in evangelio suo tradit 5 .

En el tercer y último libro del tratado se describe cómo dos caminos son necesarios para el desarrollo de la humanidad: por un lado, el de Cristo y su discípulo Pedro, fundador de la Iglesia; por otro, el de César, fundador del Imperio, y sus descendientes. La herencia del primero pervive a través de los pontífices; la del segundo, a través de los emperadores. El Imperio es el orden terrenal que conduce a los hombres a la felicidad temporal; La Iglesia representa al orden divino, que lleva a los hombres a la vida eterna. Ambos crean una unidad cosmológica emanada de Dios:

Cumque dispositio mundi huius dispositionem inherentem celorum circulationi sequatur, necesse est ad hoc ut utilia documenta libertatis et pacis commode locis et temporibus applicentur, de curatore isto dispensari ab Illo qui totalem celorum dispositionem presentialiter intuetur ${ }^{6}$.

Virgilio fue el creador del poema universal de su tiempo, el poema fundacional del pueblo romano, y sería convertido en figura literaria, que guía a Dante en su recorrido a lo largo del mundo infernal cristiano, tal y como Virgilio había sido acompañado por la Sibila en el mundo de ultratumba pagano. La prolongación de la estructura de la Eneida en el poema dantesco simboliza la continuación histórica de la época clásica en el mundo medieval.

5 Ibídem, (216). "Por consiguiente, si Cristo no hubiera padecido bajo un juez competente, aquella su pena no habría sido un verdadero castigo. Y el juez no habría podido ser competente si no tuviera jurisdicción sobre todo el género humano, ya que todo el género humano era castigado en aquella carne de Cristo, que "cargó con nuestros dolores", como dice el Profeta. Y Tiberio César, cuyo vicario era Pilato, no habría tenido jurisdicción sobre todo el género humano si el Imperio romano no hubiera sido conforme a derecho. Por eso Herodes, aunque sin saber lo que hacía, lo mismo que Caifás cuando dijo la verdad acerca del decreto divino, remitió a Cristo de nuevo a Pilato para que lo juzgara, como dice Lucas en su Evangelio". Trad. Laureano Robles Carcedo y Luis Frayle Delgado.

6 Ibídem,(275). "Y puesto que la disposición de este mundo sigue la disposición inherente a la circulación de los cielos, para que se apliquen los necesarios preceptos de la paz y la libertad oportunamente en cuanto a tiempos y lugares, es necesario además que este gobernador del mundo sea sostenido por Aquél que abarca con una sola mirada la total disposición de los cielos". 
Pero la Commedia está concebida para incluir en sí misma un modelo completo del orden cósmico. Tal y como la figura de Dios en el último círculo del Paradiso es presentada mediante tres círculos, símbolo inequívoco de la Trinidad; de la misma manera, su inverso, en el último círculo infernal, estará formado por la triple imagen de Lucifer junto a los enemigos antitéticos respectivamente del Cristianismo, orden divino, y del Imperio, orden secular: Judas Iscariote, por un lado, traidor a Cristo; y Bruto y Casio por otro, traidores a César 7 . De esta manera se consuma la alegoría completa del universo.

Esta representación negativizada del personaje de Bruto viene condicionada por las exigencias morales del Cristianismo, las cuales conducen a Dante a despojarle de su contenido heroico, con el que sí había disfrutado en la historiografía clásica, cuando era plenamente compatible la veneración al César y el respeto y admiración por sus enemigos, como explicamos al aludir a la clementia Caesaris, concepto que tal vez podría relacionarse con la moral guerrera homérica inmortalizada en el VI canto de la Ilíada, cuando el poeta de Quíos honra la memoria de Héctor y su familia antes de morir a manos del gran Aquiles. Contamos además con los famosos testimonios de la historiografía latina de descripciones henchidas de admiración a los más recalcitrantes enemigos de Roma ${ }^{8}$.

La transformación semántica y conceptual del sentido de virtud pagana (virtus, aretê), de contenido eminentemente guerrero, en la virtud moralizada del Cristianismo explica esta discrepancia de tradiciones, y la necesidad de demonizar a Bruto, que ahora pasa a ser el elemento distorsionador del orden moral dantesco, en su universo cosmológico. La transformación del concepto de pietas pagano a la piedad cristiana, es análoga a este proceso.

El poema de Dante no es sólo el eslabón cultural que une la Antigüedad con el Medioevo, es la consagración de un esquema de pensamiento que daría entrada al Humanismo y la Modernidad europeos. Es por esta razón que el cambio de visión, de un heroico resistente, al traidor a un orden político y cósmico decretado por la voluntad de Dios, iba a convertirle en una figura atractiva para la estética del Romanticismo, como el otro gran mito romántico, el titán Prometeo, el último representante de un orden precedente al nuevo poder que estableciera el dios Zeus en el mundo mitológico. Con él mantiene grandes similitudes, como veremos más adelante. Bruto constituye la oposición al ideal clásico, representado por la figura moralizada del héroe siempre triunfador, que debe moldear su caracterología siempre de acuerdo a las virtudes cristianas. Ésta es la idea subyacente del maravilloso poema de 120 versos que el gran Giacomo Leopardi, compusiera en 1821 y publicara en 1824. Su planteamiento puede observarse en un plano estético, moral y epistemológico.

7 Infierno, 34.61-67. Según Dorothy L. Sayers en Dante (1949: 42).

8 Como las magníficas descripciones de Espartaco, Plut. Crass. 8; o de Aníbal en Liv. 21, 4, y especialmente Nep. Han, 1. 
Leopardi emplea el episodio clásico en su momento más dramático. Se trata de los últimos instantes en la vida del protagonista, cuando ha sufrido la derrota decisiva. Su aliado Casio ya había cometido atentado contra su vida un día antes, en el momento de creerse derrotado, debido a un error de coordinación entre los dos generales, que hizo desaprovechar el triunfo de Bruto para suministrar refuerzos a Casio. Bruto, por lo demás, no recibió a su debido tiempo la noticia de la victoria que sus naves habían alcanzado frente a la flota cesariana, lo que en realidad le daba una clara ventaja. Finalmente, creyéndose en inferioridad, con su amigo derrotado, se arriesga a una batalla a la desesperada frente a Marco Antonio. Es entonces cuando sufre la decisiva derrota, en la que, además, tiene mucho que ver la indisciplina de las tropas de Casio, integradas ahora en su ejército9.

Al llegar la noche, el protagonista se refugia en un lugar apartado, rodeado de vegetación y flanqueado por las aguas de un arroyo. Entre algunos de sus más fieles camaradas, dirigiendo la mirada a los cielos, proclama unas últimas palabras, para acabar a continuación finalmente con su vida ${ }^{10}$. Estas palabras difieren entre las distintas fuentes clásicas que, además de la de Plutarco, tratan el episodio, según el propio Leopardi había hecho notar en su breve escrito en prosa Comparazione delle sentenze di Bruto Minore e di Teofrasto vicini a morte publicado dos años antes, en 1822. Podemos clasificar las discrepancias y coincidencias como sigue:

Las tres fuentes son coincidentes en una reflexión sobre los conceptos de Fortuna (Fortuna, Týkhē) y virtud (virtus, aretề), basada en la denuncia de que la primera, la Fortuna, ha causado la destrucción de la segunda, provocando con ello la victoria de la injusticia, en este caso representada por los cesarianos. En el caso de Floro y Dion Casio, dicha reflexión toma un valor más profundo, no sólo denunciando la derrota de la virtud, sino negando la propia existencia de la virtud:

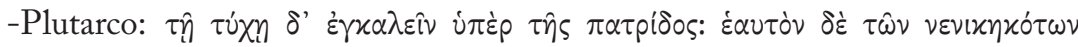

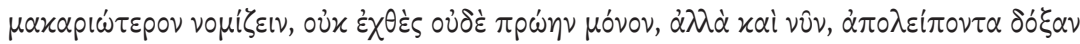

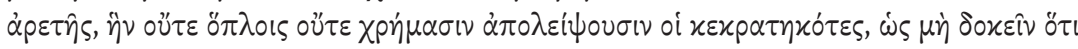

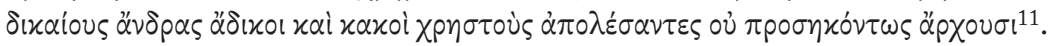

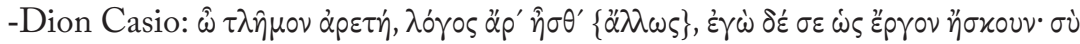

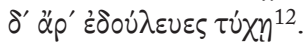

9 Plut. Bru. 42-50.

10 Ibidem, 51- 52.

11 Ibidem, "En cuanto a la fortuna, la acusa por lo que hace a la patria, pero piensa que él es más dichoso que los que han vencido, no sólo ayer ni más atrás, sino también ahora, dejando tras sí fama de virtud, que no la dejan ni con armas ni con dinero los vencedores, que parecen gobernar de manera inopinada habiendo matado ellos, malvados e injustos, a hombres justos". Trad. Juan Pablo Sánchez Hernández y Marta González González.

12 D. C. 47,49 , “¡Oh infortunada Virtud! Eras solo una palabra, y yo te convertí en acción y te ponía en práctica. ¡Pero eras esclava de la Fortuna!”. Trad. Juan Pedro Oliver Segura, Madrid, 
-Floro: "Sed quanto efficacior est Fortuna, quam virtus! Et quam verum est, quod moriens <Brutus>, non in re, sed in verbo tantum esse virtutem!" ${ }^{3}$.

Sólo en el caso de Plutarco, una apelación a la responsabilidad de Zeus como

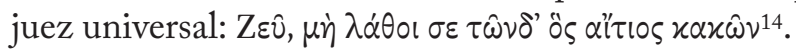

En el opúsculo en prosa mencionado, Leopardi desarrolla filosóficamente las versiones de Dion y Floro respecto a la negación del concepto de virtud, explicando que había que juzgarlas bajo un punto de vista previo a la mentalidad cristiana:

"E in ogni modo è certo che poco intendono e meno sentono la natura infelicissima delle cose umane, o si maravigliano ciecamente che le dottrine del Cristianesimo non fossero professate avanti di nascere"15.

Continuaba el poeta explicando estas referencias como indicios claros de una superación psíquica del mundo sensible: "rinnegamenti dell'intelletto umano", las denominaba, viendo en ellas el preludio de la concepción de que las cosas "fossero ombre" y no cosas. Este análisis responde a la división que, a su juicio, distinguía al hombre antiguo del moderno, fundamentada en la idea de que el primero residía inmerso en una suerte de armonía respecto a su realidad circundante, que él denominaba "età dell'immaginazione", no necesitando de la creencia en una vida después de la muerte que completase de algún modo su vida presente, o sus aspiraciones morales en ella; mientras que el segundo había perdido la unión directa con esa realidad, haciéndole ello considerar las cosas reales meras "sombras", y proyectando sus esperanzas en una vida más allá de la muerte. El desarraigo respecto al mundo terrenal, le conducía a una infelicidad inexorable, que invadía su existencia, haciéndole necesaria una recompensa en la otra vida. Mediante unas leyes dictadas desde ese otro mundo, y un sistema de recompensa y castigo, que garantizase su cumplimiento, la vida presente se reviste de un sentido moral. Sólo así la virtud se recargaría de sentido como concepto, y superaría la negación:

Laddove possiamo dire che $\mathrm{i}$ tempi di Bruto fossero l'ultima età dell'immaginazione, prevalendo finalmente la scienza e l'esperienza del vero [...] Che se ciò non fosse stato, né quegli avrebbe avuta occasione di fuggir la vita, come fece, né la repubblica romana sarebbe morta con lui $[\ldots] \mathrm{E}$ già

Gredos, 2011. La cita proviene a su vez de un autor desconocido, Frag. Trag. Graec. (Nauck, p. 910).

13 Flor. Epit. 2, 17 “Pero cuánto más poderosa es la Fortuna que la virtud! ¡Y cuán verdad es lo que dijo Bruto al morir: que sólo existe la virtud como palabra, no como realidad!". Trad. del autor.

14 Plut. Ibidem, "Zeus, no se te oculte quién es el culpable de estas calamidades". Trad. Juan Pablo Sánchez Hernández y Marta González González.

15 Leopardi (1969), "Y por otro lado, es cierto que poco entienden y menos sienten la naturaleza desdichada de las cosas humanas, o se maravillan ciegamente de que la doctrina cristiana no haya sido profesada antes de nacer". Trad. del autor. 
mancato ogni pregio a questa vita, cercavano i sapienti quel che gli avesse a consolare, [...]. Così ricorrevano alla credenza e all'aspettativa d'un'altra vita, nella quale stesse quella ragione della virtù e de' fatti magnanimi, che ben s'era trovata fino a quell'ora, ma già non si trovava, e non s aveva a trovare mai più, nelle cose di questa terra ${ }^{16}$.

Esta explicación tiene una inspiración platónica, respecto a la superación del mundo sensible hacia un mundo sobrenatural, en el que el filósofo situaba las cosas espirituales, los eídế o formas, cuya más alta expresión es la triple idea de la Belleza, el Bien y la Verdad, alegorías de los Universales, que iluminarían al hombre, respectivamente, en la ciencia estética, la ética y la epistemología.

En otro de sus opúsculos, Dialogo di Plotino e di Porfirio, de 1827, Leopardi empleaba a estos dos filósofos neoplatónicos del s. III, mediante el uso del diálogo, para profundizar en la implantación de ese nuevo esquema de valores precristianos. Porfirio era reprendido por Plotino, su maestro, por estar inmerso en una horrible melancolía, con propensiones suicidas. El discípulo replicaba violentamente, reprochándole a él y a su antecesor Platón haber despojado al hombre de su derecho a controlar su propia existencia, haciéndole temeroso de reglas externas, fundamentadas en el temor a crueles castigos, que los jueces de ultratumba Minos, Radamantis y Éaco le habrían de imponer. Estos jueces pertenecen al famoso mito que Platón había introducido en su diálogo Gorgias, como es bien sabido ${ }^{17}$, y estaban encargados de juzgar a las almas después de muerte, de acuerdo a las huellas o vestigios que sus pecados dejarían impreso en ellas, (de la misma manera en que las heridas físicas dejaban una cicatriz en el cuerpo físico, nos decía). Éste sería, si no el primero, el más importante ejemplo de sublimación ética de la creencia en una vida ultraterrena, y por tanto el germen de la dualidad cristiana de la salvación frente a condenación. Es evidente que este antecedente está en la mente de Dante cuando describe su personal Inferno, y sitúa a uno de estos jueces, Minos, como el encargado de determinar los castigos apropiados a cada pecador en el segundo círculo.

En cuanto a la segunda declaración de Bruto, la recogida por Plutarco en torno a Zeus, cuando proclama "Zeus, no se te oculte el culpable de estos males", nos advierte de la condición suprema de esta divinidad: ser el garante de la justicia universal. A su vez preludia la idea de Dios monoteísta. La idea de que la victoria de Octavio era parte de un plan divino, está presente en Plutarco

16 Ibidem, "Mientras podríamos decir que los tiempos de Bruto fueron la última edad de la imaginación, prevaleciendo finalmente la ciencia y la experiencia de la verdad (...). Porque si esto no hubiera ocurrido, ni aquel habría tenido ocasión de huir de la vida, como hizo, ni la República romana habría muerto con él (...) Y ya perdido todo aprecio por esta vida, buscan los sabios aquello que les hubiese de consolar, (...). Así recurrían a la creencia y esperanza en otra vida, en la que se hallara aquella razón de la virtud y de los hechos magnánimos, que bien se encontrara hasta entonces, pero ya dejóse de encontrar, y no habría de encontrarse en adelante en las cosas de este mundo". Trad. del autor.

17 P1. Grg. 523e-524a. 
mismo, recogiendo el providencialismo virgiliano. Así lo indicaba al referirse a la razón por la cual Bruto no supo de su victoria marítima, información que le habría dado una gran ventaja:

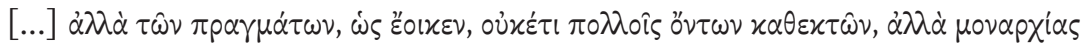

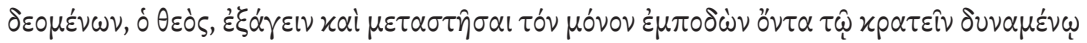

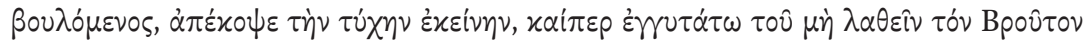

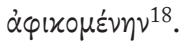

La interpretación de Leopardi entiende la apelación a la vacuidad de la virtud como la constatación del final de un período histórico. Bruto, en su aliento final, antes de cometer atentado contra su vida, despierta de la era de la "imaginación" y descubre que sus antiguos valores no son suficientes para conducirle a la victoria, porque asiste al comienzo de una nueva época, en la que un plan gestado por la divinidad iba a dar el poder a quienes estaban destinados a poseerlo. Él es el perfecto héroe romántico, y la antítesis del ideal clásico. Representa la oposición a los valores cristianos, que fueron la base para crear al héroe del Clasicismo europeo, figura ejemplarizante y siempre triunfadora. La oposición moral tiene un correlato en el ámbito estético, e igualmente en el ámbito epistemológico, dentro de la órbita de las corrientes irracionalistas románticas que pondrán en duda la infalibilidad de los esquemas racionales que habían dominado el pensamiento occidental desde el nacimiento de la filosofía. La Commedia representaba una alegoría de una cosmovisión medieval, en la que los círculos celestiales eran concebidos como representación de las diferentes ciencias, que emanaban, en última instancia, de Dios. Leopardi utiliza su mismo código alegórico para atacar ese sistema, retomando a la figura que representaba la oposición a la obra de Dios, el traidor al orden terrenal, exaltándole y recreándose en la intensidad de su caída.

Éstas son las fuentes y bases ideológicas del poema. El concepto de la virtud da comienzo a la pieza: "Poi che divelta, nella tracia polve/ giacque, ruina immensa,/ l'italica virtude..."19, donde habla el autor, hasta que da paso en estilo directo al propio Bruto, quien asimismo comienza su intervención con una apelación al mismo concepto: "Stolta virtù, le cave nebbie, i campi/ dell'inquiete larve/ son le tue scole, e ti si volge a tergo/ il pentimento" 20 . La primera referencia hace hincapié en el aspecto político de la virtud, el segundo incide en su interpretación

18 Plut. Brut. 47, 4, "Pero como la situación, según parece, ya no podía ser manejada por muchos sino que requería una monarquía, la divinidad, queriendo apartar y retirar al único que podía ser un obstáculo para ese poder absoluto, mantuvo apartada aquella noticia, aunque estuvo muy cerca de ser conocida por Bruto”. Trad. Juan Pablo Sánchez Hernández y Marta González González.

19 G. Leopardi, (1998), "Cuando arrancada, sobre el polvo tracio/ yació cual ruina inmensa/ la itálica virtud...”. Trad. María de las Nieves Muñiz Muñiz, Madrid: Cátedra, 1998.

20 Ibidem, vv. 16-19 "Necia virtud, la huecas niebla, el campo/ de las inquietas larvas/ son tu escuela, y en pos de ti camina/ paso a paso el pesar”. Trad. María de las Nieves Muñiz Muñiz. 
metafísica. La apelación a Zeus de Plutarco ha sido ampliada y reforzada en su sentido de denuncia contra el orden moral y la justicia universal que representa: "Dunque tanto i celesti odii commove/ la terrena pietà? dunque degli empi/ siedi, Giove, a tutela? e quando esulta/ per l'aere il nembo, e quando/ il tuon rapido spingi/ ne'giusti e pii la sacra fiamma stringi?"21.

Ante esta situación de tiranía universal el héroe no buscará la resignación, sino la resistencia: "Guerra mortale, eterna, o fato indegno,/ teco il prode guerreggia,/ di cedere inesperto; e la tiranna/ tua destra, allor che vincitrice il grava,/ indomito scrollando si pompeggia"22.

Bruto se lamenta de la armonía natural perdida, de esa "era de la imaginación": "Non fra sciagure e colpe,/ ma libera ne' boschi e pura etade/ natura a noi prescrisse,/ reina un tempo e Diva"23. La única posibilidad de escapar, tal como defiende Porfirio ante su maestro Plotino, es el suicidio, el derecho a la propia autodestrucción. Los animales, no sujetos a leyes morales, conservan ese derecho: "Ma se spezzar la fronte/ ne' rudi tronchi, o da montano sasso/ dare al vento precipiti le membra,/ lor suadesse affanno/ al misero desio nulla contesa/ Legge arcana farebbe/ o tenebroso ingegno" 24 . Sin embargo los hombres, "los hijos de Prometeo", están condenados a la infelicidad, y Júpiter les impide el suicidio: "A voi, fra quante stirpi il cielo avvivò, soli fra tutte, figli di Prometèo, la vita increbbe; a voi le morte ripe, se il fato ignavo pende, soli, o miseri, a voi Giove contende" 25 .

Jove impide a los hombres asumir su autodestrucción, y el poeta se refiere a ellos aquí, no gratuitamente, como los "hijos de Prometeo", de quien heredaron la culpa de la rebelión contra la divinidad suprema. El titán Prometeo es el último representante de la generación de dioses previa a la rebelión que Zeus dirigió contra su padre Cronos, imponiendo un nuevo orden cósmico. El proporciona el fuego del conocimiento a la humanidad, en castigo de lo cual Zeus le encadena en las montañas del Cáucaso e in troduce en los hombres el germen de las guerras, las enfermedades y el trabajo, tal y como ilustrara Hesíodo con su conocido mito de Pandora ${ }^{26}$. Uno de los ejemplos más representativos de la recepción de la

21 Ibidem,vv. 25-30 “¿Tales odios despierta en las alturas/ la terrena piedad? ¿De impíos eres,/ Júpiter protector? Y cuando rompe/ los aires la tormenta y cuando el trueno/ arrojas cual saeta,/ ¿la sacra llama contra el justo aferras?".

22 Ibidem, vv. 38-42 "Guerra mortal, eterna, indigno hado,/ a ti te hace el valiente,/ de rendirse inexperto; y si triunfante/, esa diestra tirana lo aplastara,/ sacudiéndola indómito se yergue”.

23 Ibidem, vv. 52-55 "No entre dolor y culpas,/ sino libre en los bosques, pura vida/ nos prescribió Natura,/ diosa antaño y señora”.

24 Ibidem, vv. 64-70 "Mas si a romper la frente/ en rudo tronco, o por algún barranco/ y a dispersar sus miembros por el aire,/ el dolor las llevase;/ al mísero deseo veto alguno/ ley arcana opondría/ o tenebroso ingenio".

25 Ibidem, vv. 70-75 "Mas de cuantas/ el cielo creó estirpes, a vosotros,/ hijos de Prometeo, odio tan sólo/ esta vida inspiró; y la muerta orilla,/ si el hado ocioso pende,/ Júpiter, infelices, os contiende".

26 Hes. Op. 43- 106. 
figura de Prometeo en el Romanticismo europeo es el siguiente poema de J. W. von Goethe, del que reproducimos un fragmento en lengua original, aunque no es la única obra que le dedicaría al titán:

\author{
Bedecke deinen Himmel, Zevs, \\ Mit Wolkendunst, \\ Und übe, dem Knaben gleich, \\ Der Disteln köpft, \\ An Eichen dich und Bergeshöhn [...] \\ Ich kenne nichts Aermeres \\ Unter der Sonn' als euch, Götter! \\ Ihr nähret kümmerlich \\ Von Opfersteuern \\ Und Gebetshauch \\ Eure Majestät ${ }^{27}$.
}

Son muchas las similitudes filosóficas que unen a Leopardi y Nietzsche ${ }^{28}$. La dicotomía entre armonía primigenia frente a una segunda naturaleza racionalreligiosa, es análoga a la que encontramos, como es bien sabido, en el clásico y polémico trabajo del filósofo alemán, El nacimiento de la tragedia, entre el mundo dionisíaco y apolíneo. El hombre "trágico" nietzscheano está en comunión con lo que él denominaba el "uno primordial", que es un mundo de infinito sufrimiento; frente al velo de ensoñación, representado poéticamente por el dios Apolo, que coincide con la racionalidad y el "principio de individuación", que nos permite ordenar la realidad. Nietzsche citaba el mencionado poema goethiano, mediante el que quería ilustrar la distinción moral existente entre la tradición judeocristiana, basada en el pecado de Adán; y la del paganismo, basada en el crimen de Prometeo. Éste último le vale al hombre el ser expulsado de la Edad de Oro; el de Adán, el ser expulsado del Edén:

Die Prometheussage ist ein ursprüngliches Eigenthum der gesammten arischen Völkergemeinde und ein Document für deren Begabung zum Tiefsinnig-Tragischen, ja es möchte nicht ohne Wahrscheinlichkeit sein, dass diesem Mythus für das arische Wesen eben dieselbe charakteristische Bedeutung innewohnt, die der Sündenfallmythus für das semitische hat, und dass zwischen beiden Mythen ein Verwandtschaftsgrad existiert, wie zwischen Bruder und Schwester ${ }^{29}$.

27 Goethe (1789: 207-209) "Prometheus" (Gedicht, frühe Fassung), vv. 1-5, 12-17, "Cubre tu cielo, Zeus, con un velo de nubes, y juega, como un muchacho que descabeza cardos, / con encinas y montañas;(...) ¡No conozco nada más miserable bajo el sol/ que vosotros, dioses!/ alimentáis pobremente mediante sacrificios /y aliento de oraciones/ vuestra majestad". Trad. del autor.

28 Cf. Crespi (2009)

29 Nietzsche (1967) "La leyenda de Prometeo es posesión originaria de la comunidad entera de los pueblos arios y documento de su aptitud para lo trágico y profundo, más aún, no sería inverosímil que ese mito tuviese para el ser ario el mismo significado característico que el mito 
La rebeldía de Prometeo frente al poder de Zeus representa para el filósofo la supremacía de la tradición pagana frente a la judeocristiana, a la que más adelante, en La Genealogía de la moral, calificaría con su famosa expresión "moral de esclavos". Frente a la sumisión del Adán hebreo ante el castigo divino por su pecado, el Prometeo indoeuropeo, o "ario", muestra una afirmación activa:

[...] ein herber Gedanke, der durch die Würde, die er dem Frevel ertheilt, seltsam gegen den semitischen Sündenfallmythus absticht, in welchem die Neugierde, die lügnerische Vorspiegelung, die Verführbarkeit, die Lüsternheit, kurz eine Reihe vornehmlich weiblicher Affectionen als der Ursprung des Uebels angesehen wurde. Das, was die arische Vorstellung auszeichnet, ist die erhabene Ansicht von der activen Sünde als der eigentlich prometheischen Tugend ${ }^{30}$.

Existe una relación poética entre Prometeo y Bruto. Tal como el titán, miembro de una generación de dioses más antigua a la de Zeus, es decir, de un orden cósmico precedente, yace encadenado en lo recóndito del Cáucaso, así el héroe Bruto suspira su último aliento en los páramos de Macedonia, consciente de que el orden en que ha creído es suplantado por un poder mucho mayor. "Los hijos de Prometeo" han sido expulsados del paraíso, y en consecuencia se han visto relegados a una existencia de completa infelicidad, vetándoseles incluso su derecho a huir mediante el suicidio. Cuanto les queda es la resistencia activa, la firme oposición ante la doble tiranía divina y terrenal, pero esa resistencia será finalmente solapada por la humillación que supone la moral del judeocristianismo, representada por el pecado de Adán, que para Dante debía ser expiado por el castigo de Cristo. Bruto descubre que la virtud es una mera palabra, y se da cuenta de que la humanidad, en adelante, necesitará de un marco de referencia que dé sentido a nuevos conceptos. Ese marco de referencia será lo que Nietzsche llamaba "mundo apolíneo", y que coincidirá con el mundo de las ideas platónicas, germen del pensamiento cristiano.

Para Leopardi, finalmente, la muerte no es un camino a un mundo mejor, sino hacia la Nada. El acto mismo de la muerte es el que merece la pena, el que cobra valor. Es el único consuelo que le queda al hombre: la autodestrucción. Da un sentido nuevo por tanto al suicidio estoico, del cual la muerte de Bruto era ya ejemplo prototípico, junto a la de Catón uticense y Séneca.

del pecado original tiene para el ser semítico, y que entre ambos mitos existiese un grado de parentesco igual al que existe entre hermano y hermana” Trad. Andrés Sánchez Pascual, Madrid: Alianza Editorial, 1973.

30 Ibidem, “(...) es éste un pensamiento áspero, que, por la dignidad que confiere al sacrilegio, contrasta extrañamente con el mito semítico del pecado original, en el cual se considera como origen del mal la curiosidad, el engaño mentiroso, la facilidad para dejarse seducir, la concupiscencia, en suma, una serie de afecciones preponderantemente femeninas. Lo que distingue a la visión aria es la idea sublime del pecado activo como virtud genuinamente prometeica”. Trad. Andrés Sánchez Pascual. 
Los restos de Leopardi fueron llevados en 1939 al Parque Virgiliano de Piedigrotta, a la salida de la Crypta Neapolitana o Gruta de Posilipo en Nápoles ${ }^{31}$, donde, según la tradición, estarían también los restos de Virgilio, como atestiguaba el propio Dante: "Vespero e giat cola dov' e sepolto/ Lo corpo dentro al quale io facea ombra;/ Napoli l'ha, e da Brandizio e tolto" 32 . Así la realidad juega con la poesía, cerrándose un círculo que abre la Eneida, continúa la Commedia, y cierra el autor de Bruto Minore. De este modo el pensamiento filosófico y estético es construido siempre en contraposición a sus antecedentes, pero sobre la firme base que los mismos establecen, creando un recorrido dialéctico. El Clasicismo pagano es reutilizado para la creación de la ideología cristiana medieval, eslabón necesario para el desarrollo del racionalismo moderno. Pero las verdades racionales y la firme confianza en la capacidad del conocimiento humano, entrará en una profunda crisis con la llegada del Romanticismo, tanto en el ámbito de la estética, pero también en el ámbito epistemológico, de lo cual será manifestación el irracionalismo de Nietzsche y la rebeldía de Leopardi.

Mediante la recepción literaria de un personaje podemos recorrer todo este proceso histórico. Un héroe que despertaba la admiración de sus enemigos en el mundo pagano, el vil traidor al orden divino en Dante, y finalmente el representante de la rebeldía ante la tiranía de ese orden religioso-racional para Leopardi.

\section{BIBLIOGRAFÍA}

Crespi, S. (2009): "Nietzsche e Leopardi a confronto", Laboratorio sulle Operette Morali di Leopardi, <http://www.agenziaimpronta.net/archivio/operette_morali_ relaz_crespi.pdf>. (17-08-2014).

Dante Alighieri (1992): Monarquía. Estudio preliminar, traducción y notas: Laureano Robles Carcedo y Luis Frayle Delgado. Madrid: Tecnos.

Dante Alighieri (1949): The Divine Comedy, "Hell". Traducción e introducción: Dorothy L. Sayers, Harmondsworth: Penguin Classics.

Dante Alighieri (1965): Monarchia, Milano: Società Dantesca Italiana.

Dante Aligheri (1976): Comedia, Barcelona: Seix Barral.

Goethe, J.W. (1789): Goethes Scbriften, VIII. Leipzig: Göschen.

Leopardi, G. (1998): Cantos. Madrid: Cátedra.

Leopardi, G. (1969): "Operette morali, di Giacomo Leopardi" en Binni, Walter/ Ghidetti, Enrico (eds.): Tutte le opere, I. Firenze: Sansoni Editore.

Nietzsche, F. (1967) Werke. Die Geburt der Tragödie. Oder: Griechenthum und Pessimismus <http://www.nietzschesource.org> (26 octubre 2014).

31 Trapp (1984: 31).

32 Ibidem, (1). La cita proviene de Dante, Purgatorio, III. 25-27 "Véspero se halla ahora do enterrado/ mi cuerpo está, que sombra proyectara:/ a Nápoles de Brindis fue llevado”Trad. Ángel Crespo, Barcelona: Seix Barral, 1976. 
Nietzsche, F. (1973): El nacimiento de la tragedia. Madrid: Alianza Editorial.

Novillo López, M.A. (2013): "La clementia Caesaris: virtud propia del buen gobernante", Debita Verba 1, 739-748.

Plutarco (2009): Vidas paralelas. VII: Demetrio-Antonio, Dión-Bruto, Arato, ArtajerjesGalba, Otón. Introducciones, traducción y notas de Juan Pablo Sánchez Hernández y Marta González González. Madrid: Gredos.

Trapp, J.B. (1984): “The grave of Vergil”, Journal of the Warburg and Courtauld Institutes $47,1-31$.

Nombre del autor: Rafael Sáseta Naranjo

Dirección-e: ego_narcisus@hotmail.com

Dirección postal: $\quad$ c/ Calatayud, 12, C.P. 41006, Sevilla

Fecha de recepción: 17/08/2014

Fecha de aceptación: 06/11/2014 